\title{
Applying Children's Quality of Life Assessment to Promote the Reliability of Children Dental Health Services Quality
}

\author{
Taufan Bramantoro', Yayi Suryo P², Djauhar Ismail $^{3}$, Udijanto Tedjosasongko ${ }^{4}$
}

\begin{abstract}
Objective: Dental health services as a service provider need to evaluate and promote their service quality. The assessment of oral health related quality of life can be valuable material for the planning and evaluation of dental health services. Oral health related quality of life assessment apply the socio-dental indicators aspects and provide information in regard to the impact of oral conditions on the quality of life. One of patient's service quality assessment main aspect is reliability of dental treatment. Reliability of dental treatment is not only focused on dental pathological problems solving, but also on patient's quality of life improvement. This study examined the application of children's quality of life assessment as a decision planning basis to promote reliability aspects in children dental health services quality.
\end{abstract}

Material \& Method: This study can be considered as an observational analytic research using cross-sectional study design. This research was conducted in Wates Mojokerto Community Dental Health Service in the early 2015. The population in this research involved children aged 3-5 years who had dental caries and also were students in kindergarten and early childhood program in Wates Mojokerto Community Dental Health Service as well as their mothers. Thus, the total of the population in this research was 309 children and their mothers. The instrument used in this study was measurement instrument of children's oral health related quality of life, which had been tested for their validity and reliability.

Results: That the number of dental caries had a considerable effect on the children's quality of life aged 3-5 years. Children who become fussy or anxious had the highest frequency of insidence than other impacts. There were significant differences of the number of dental caries among of the insidence of quality of life impacts.

Conclusion: The results described that fussy or anxious condition of children was the priority factor for parents in assessing the reliability aspects of dental health services quality in Wates Mojokerto Community Dental Health Service. This information becomes valuable input for Wates Mojokerto Community Dental Health Service in planning effective and reliable dental treatment procedures for children.

Keywords: Service quality, Children oral health, Children quality of life, Dental health services.

$\begin{array}{cll}\text { Contact Autbor } & \begin{array}{c}{ }^{1} \text { Lecturer } \\ \text { Department of Dental Public Health, }\end{array} & \begin{array}{c}{ }^{3} \text { Professor } \\ \text { Department of Pediatrics, } \\ \text { Dr. Taufan Bramantoro }\end{array} \\ \text { tbramantoro@gmail.com } & \text { Faculty of Dentistry, Airlangga University } & \text { Faculty of Medicine, Gadjah Mada University } \\ & \begin{array}{l}\text { 2. Senior Lecturer } \\ \text { Department of Public Health, }\end{array} & { }^{4} \text { Senior Lecturer } \\ \text { Department of Pediatric Dentistry, } \\ \text { J Oral Health Comm Dent 2016;10(1)9-13 } & \text { Faculty of Medicine, Gadjah Mada University } & \text { Faculty of Dentistry, Airlangga University }\end{array}$




\section{INTRODUCTION}

$\mathrm{O}$ ral health has significant role related quality of life and become an integral part of health. Most oral disease have consequences or impacts in quality of life. Therefore, the methods of measuring oral health do not only use clinical dental indicators, but also focus on the presence or absence of oral disease related with quality of life. Oral health related quality of life assessment method describes the function of socio-dental indicators concept relating non-clinical factors of oral health with the improvement of dental health service quality $(1,2)$. Furthermore, oral health related quality of life assessment method describes the non-clinical health outcomes of oral disorders and fullfil clinical indicators to erect a comprehensive information of the health of individuals and populations $(2,3)$.

Prevention and treatment efforts concerned with dental caries problems in children require further and special attention. It is because dental caries problem in children not only have potential to evolve, but also have a significant impact on the children's quality of life associated with disorders of masticatory system and child daily activities. However, the planning efforts of dental caries prevention and treatment are not only focused on its clinical impact, but must also be focused on the assessment and measurement of its impact on the quality of life, especially related to dental health problems. Oral health problems that are chronic, along with their symptom development and their effects in line with style and lifestyle, demand the need for assessment method for their chronic impact, both socially and psychologically, instead of their clinical indicators $(4,5)$.

Applying oral health status assessment comprehensively, observation must be conducted individually or in groups, not only involving the existence of diseases, but also the status of physical function, psychological function, social function, and satisfaction with health. In other words, it can be assumed that the aspects of quality of life are important in planning and assessment processes related to the effectiveness of oral health program. Quality of life assessment can provide a powerful additional dimension in the planning and evaluation of health promotion programs. Thus, the assessment must be associated with the consideration of efforts made by a person in accepting the delivery of oral health programs in order to improve the quality of his dental and oral health (5-7).

The assessment of oral health related quality of life can be valuable material for the planning and evaluation of dental health services. Oral health related quality of life assessment apply the socio-dental indicators aspects and provide information in regard to the impact of oral conditions on the quality of life $(8,9)$.

Dental health services as a service provider need to evaluate and promote their service quality. One of patient's service quality assessment main aspect is reliability of dental treatment. Reliability of dental treatment is not only focused on dental pathological problems solving, but also on patient's quality of life improvement related with dental treatment results. Oral health related quality of life assessment describe in regard to the impact of oral conditions on the quality of life. This study examined the application of children's quality of life assessment as a decision planning basis to promote reliability aspects in children dental health services quality. Understanding children's assessments in quality of life become valuable input in planning of children dental health services quality improvement programs.

\section{MATERIAL \& METHOD}

This research is an observational analytic research using cross-sectional study design. This research was con- ducted in Wates Mojokerto Community Dental Health Service in the early 2015. The population in this research involved children aged 3-5 years who had dental caries and also were students in kindergarten and early childhood program in Wates Mojokerto Community Dental Health Service as well as their mothers. Thus, the total of the population in this research was 309 children and their mothers.

Moreover, the number of dental caries in children refers to the total number of deciduous teeth in the oral cavity of children, which got dental caries, lost due to dental caries, and filled. Assessment of the quality of those children's life was based on their mother's perception related to how big the disruption of their children's quality of life and normal activities was as a result of dental health. The assessment was in the form of a mean value. The assessment involved three aspects, namely physical aspects, functional aspects, and psychological aspects. Thus, questionnaire used to measure the impact of the quality of those children's life was adapted from the synthesis of some measuring instruments of the children's quality of life that had been developed previously (10-12).

There were several questions delivered as an instrument for measuring the influence of the dental health of children aged 3-5 years on the children's quality of life. Those questions had successfully been tested for their validity and reliability. Those questions were as follow: "Did your child ever feel fussy / anxious?", "Did your child ever feel unwilling or uncomfortable to eat and drink?","Is your child ever absent from school?","Did your child never sleep or feel difficulty in sleeping?". The answers of those questions were "Ever" and "Never". The answer "Ever" was given a score of 1, while "Never" was given a score of 2 .

Finally, before starting to fill out the questionnaire and dental examination 
of their children, those mothers were given informed consent which had to be signed by them as their approval to participate as research samples. Next, this research was approved by Medical and health research ethics committee of Medicine Faculty of Gadjah Mada University.

Frequency and mean tables were generated for various categorical and continuous variables. Independent t-test analysis were used for comparing to the number of dental caries in children of the impacts on children's quality of life.

\section{RESULTS}

Based on the data obtained in this research, it can be considered that the distribution of sex between boys and girls was equal, namely 159 boys $(51.5 \%)$ and 150 girls (48.5\%).

Based on Table 1, it can be seen that the average number of dental caries in children aged 3-5 years in the group of children whose family expenditure per month less than $\leq 1.485$ million com- pared to that in the group of children whose family expenditure per month more than $>1.485$ million. Similarly, it can be known that the children's quality of life in the group of children who have more than two siblings was lower than that in the group of children who have no or two siblings.

Based on table 2, in all the groups of quality of life impacts, it is generally found that the number of dental caries had a considerable effect on the children's quality of life aged 3-5 years. Children who become fussy or anxious had the highest frequency of insidence than other impacts. It can be seen from the data that there were significant differences of the number of dental caries among of the insidence of quality of life impacts.

\section{DISCUSSION}

Oral health has an important role associated with the oral stomatognatic functional and the productivity. Moreover, Oral health condition has impacts on various aspects of quality of life, including oral function, appearance, and interpersonal relationships. Dental health services are comprehensive that integrated the improvement, prevention, healing, and rehabilitation efforts of oral health functional. Dental health service providers need to understand in regard to patients perspective on dental treatment outcomes to improve service quality for better dental treatment outcomes and to achieve the effectiveness and efficiency of dental health service (13). According to the result of this study illustrated that there were some priority aspects in parents perspective regarding their children's quality of life assessment related with dental treatment outcomes.

Moreover, dental caries in early childhood can cause disruptions or negative impacts on the children's quality of life. For example, dental caries can cause painful disorders, discomfort in mouth, chewing disorders, speech disorders, discomfort in playing or learning, and sleeping disorders. These disorders can then lead to pressure or

\begin{tabular}{|c|c|c|c|c|}
\hline \multirow[t]{2}{*}{ Mother's characteristics } & \multirow[t]{2}{*}{ Group } & \multirow[t]{2}{*}{ Frequency } & \multicolumn{2}{|c|}{ Quality of Life } \\
\hline & & & Mean & SD \\
\hline \multirow[t]{2}{*}{ Family Expenditure per month } & $\leq 1.485 .000$ & $105(34 \%)$ & 1.593 & 0.328 \\
\hline & $>1.485 .000$ & $204(66 \%)$ & 1.639 & 0.343 \\
\hline \multirow[t]{2}{*}{ Number of children living at the same house with their parents } & $>2$ children & $57(18.4 \%)$ & 1.583 & 0.351 \\
\hline & $\leq 2$ children & $252(81.6 \%)$ & 1.633 & 0.335 \\
\hline
\end{tabular}

Table 2 : Description and Distribution of Child Dental Caries Impact on Quality of life based on Child Dental Caries

\begin{tabular}{|c|c|c|c|c|c|}
\hline \multirow[t]{2}{*}{ Quality of life Impacts } & \multirow[t]{2}{*}{ Incidence } & \multirow[t]{2}{*}{ Frequency } & \multicolumn{2}{|c|}{ Dental caries } & \multirow[t]{2}{*}{$\mathrm{p}$ value } \\
\hline & & & Mean & D & \\
\hline \multirow[t]{2}{*}{ Did your child ever feel fussy / anxious? } & Ever & $159(51,5 \%)$ & 10,566 & 4,576 & 0,000 \\
\hline & Never & $150(48,5 \%)$ & 4,967 & 3,726 & \\
\hline \multirow[t]{2}{*}{ Did your child ever feel unwilling or uncomfortable to eat and drink? } & Ever & $130(42,1 \%)$ & 11,408 & 4,607 & 0,000 \\
\hline & Never & $179(57,9 \%)$ & 5,263 & 3,529 & \\
\hline \multirow[t]{2}{*}{ Is your child ever absent from school? } & Ever & $73(23,6 \%)$ & 12,986 & 4,529 & 0,000 \\
\hline & Never & $236(76,4 \%)$ & 6,259 & 4,019 & \\
\hline \multirow[t]{2}{*}{ Did your child never sleep or feel difficulty in sleeping? } & Ever & $102(33 \%)$ & 11,726 & 4,672 & 0,000 \\
\hline & Never & $207(67 \%)$ & 5,937 & 4,005 & \\
\hline
\end{tabular}


stress in children, especially requiring medication. Social and psychological disorders occurred in early childhood will also have a negative impact on the decreasing of the children's quality of life $(14,15)$. It is because dental caries can trigger pain caused by inflammatory processes in dental caries, limited function of teeth, and psychological discomfort (16).

Similarly, in another study it is known that there were several common problems associated with the influences of child dental caries on the quality of their life, such as their self-empowerment to learn and play, their ability to chew food well, their ability to drink hot or cold drinks, their sociability, and their sleeping activity. In other words, it can be said that the children's quality of life is a factor often affected by dental caries. Severe dental caries in early childhood even can also become a potential disruption for their pronunciation ability and their growth $(4,16-18)$.

Oral health related quality of life assessment does not only help dental health service providers to evaluate the effectiveness of dental treatment, but also has benefit in identifying determinants of health risk factors and examining the perceived value of dental health service quality. Therefore, quality of life assessment affect the development of service quality programs and institutional priorities $(19,20)$.

Evaluation and assessment of dental treatment outcomes was observed not only from the solved of the pathological impacts of the dental problems, but also the quality of life as an analysis of the impact of dental treatment on their life performances. Quality of life assessment has a significant role in building the thinking perspective of person's psychology, including the assessment or perception and motivation based on theirs experience. Health services use quality of life assessment to analyze patients emotional, social, and physical abilities, including the ability to fulfill the demands of achieving the best treatment outcomes for patient $(1$, 19, 20). Dental treatment has objectives to improve the quality of life related to oral health that illustrate the positive impacts of the oral condition in social functional, physical, psychological, and economically. On the other hand, dental health problems can potentially degrade the quality of life related to oral health condition.

Oral health related quality of life assessment as an individual's assessment measure regarding the affect of his or her well-being, functional factors, psychological factors, social factors, and experience of pain or discomfort in relation to orofacial concerns. Moreover, quality of life has terminology as an individual's perception of his or her position in life, in the perspective of the culture and social value systems. The quality of life also has relation to their goals, expectations, mental, physical, and social functioning $(19,20)$.

Oral health related quality of life assessment method that using socio-dental indicators assess and provides information regarding the impact of oral conditions on the individual's quality of life. The quality of life assessment can be applied for evaluating of the dental health needs and planning of dental health services quality programs. Therefore, examining children's oral health related quality of life is used to determine parents and children perspectives on dental health service needs and outcomes. Understanding parents priority perspective in their children's quality of life aspects can be optimalized as an important material for strategic development of children dental health service quality.

\section{CONCLUSION}

The results described that the number of dental caries had a considerable effect on the children's quality of life aged 3-5 years. Children who become fussy or anxious had the highest frequency of insidence than other impacts. There were significant differences of the number of dental caries among of the insidence of quality of life impacts. That fussy or anxious condition of children was the priority factor for parents in assessing the reliability aspects of dental health services quality in Wates Mojokerto Community Dental Health Service. This information becomes valuable input for Wates Mojokerto Community Dental Health Service in planning effective and reliable dental treatment procedures for children.

\section{REFERENCES}

1. Brennan DS, Singh KA, Spencer AJ, Thomson KFR. Positive and negative affect and oral health-related quality of life. Health and Quality of Life Outcomes 006;4:83.

2. Slade GD, Strauss RP, Atchison KA, Kressin NR, Locker D, Reisine ST. Conference summary: assessing oral health outcomes, measuring health status and quality of life. Community Dent Health 1998;15:3-7.

3. Jokovic A, Locker D, Stephens M, Kenny D, Tompson B, Guyatt G. Validity and Reliability of a Questionnaire for Measuring Child Oral-health-related Quality of Life. J Dent Res 2002;81;459.

4. Abanto J, Carvalho TS, Fausto MM, Marcia TW, Marcelo B, Daniela PR. Impact of oral diseases and disorders on oral health-related quality of life of preschool children. Community Dent Oral Epidemiol 2011;39:105-14.

5. Petersen PE, Kwan S. Evaluation of community-based oral health promotion and oral disease prevention - WHO recommendations for improved evidence in public health practice. Community Dental Health 2004;21(Supplement): 319-329.

6. Hobdell M, Petersen PE, Clarkson J, Johnson N. Global goals for oral health 2020. International Dental Journal 2003;53:285-88.

7. Sischo L, Broder HL. Oral Healthrelated Quality of Life: What. Why. How. and Future Implications. J Dent Res 2011;90(11):1264-70.

8. Nuca C, Amariei C, Rusu DL, Arendt C. Oral health-related quality of life evaluation'. University of Constanta, Romania. OHDMBSC 2007;6:3-8.

9. Kumar $S$, Bhargav $P$, Patel A, Bhati M, Balasubramanyam G, Duraiswamy P, Kulkarni S. Does dental anxiety influence oral health-related quality of life? Observations from a crosssectional study among adults in Udaipur district, India'. Journal of Oral Science 2009;51:245-54. 
10. Pahel BT, Rozier RG, Slade GD. Parental perceptions of children's oral health: The Early Childhood Oral Health Impact Scale (ECOHIS). Health and Quality of Life Outcomes 2007;5:6.

11. Tsakos G, Blair YI, Yusuf H, Wright W, Watt RG, Macpherson LMD. Developing a new self-reported scale of oral health outcomes for 5-year-old children (SOHO-5). Health and Quality of Life Outcomes 2012;10(62).

12. Susilawati $S$, Djuharnoko $P$, Syaefullah A, Kartini Sari. D. Caries and Quality of Life - Evidence of Impacts from Indonesia. Presentation on 7 th asian conference oforal health promotion for school children. Bali. 2013

13. Klages U, Bruckner A, Zentner A. Dental Aesthetics, Self Awareness, and Oral Health related Quality of Life in Young
Adults. European Journal of Orthodontics 2004;26:507-14.

14. Moynihan P, Petersen PE. Diet. nutrition and the prevention of dental diseases. Public Health Nutrition 2004;7(1A): 201-22.

15. Low W, Tan S, Schwartz. S. The effect of severe caries on the quality of life in young children. Pediatric Dentistry 1999; 21(6):325-26.

16. Filstrup SL, Briskie D, Marcio da F, Lawrence L, Wandera A, Inglehart MR. Early Childhood Caries and Quality of Life: Child and Parent Perspectives. Pediatric Dentistry 2003;25(5):431-440.

17. Feitosa S, Colares V, Pinkham J. The psychosocial effects of severe caries in 4-year-old children in Recife. Pernambuco. Brazil. Cad Saude Publica
2005;21:1550-56.

18. Martins-Junior PA, Vieira-Ansdrade RG, Correa-Faria P, Oliveira-Ferreira F, Marques LS, Ramos-Jorge ML. Impact of Early Childhood Caries on the Oral Health-Related Quality of Life of Preschool Children and Their Parents. Caries Res 2013;47:211-18.

19. Inglehart MR, Bagramian RA. Oral healthrelated quality of life: an introduction. In Oral Health-related Quality of Life. Inglehart MR, Bagramian RA eds, Quintessence Publishing, Chicago,2002. 1-6.

20. Allen PF. Assessment of oral health related quality of life. Health and Quality of Life Outcomes 2003;1:40. 